17. Hey EN 1969 The relation between environmental temperature and oxygen consumption in the newborn baby. J Physiol (Lond) 200:589

18. Jammes Y, Auran Y, Gouvernet J, Delpierre S, Grimand C 1979 The ventilatory pattern of conscious man according to age and morphology. Bull Eur Physiopathol Respir 15:527

19. Kirkpatrick SML, Olinsky A, Bryan MH, Bryan AC 1976 Effect of premature delivery on the maturation of the Hering-Breuer inspiratory inhibitory reflex in huam infants. J Pediatr 88:1010

20. Lynne-Davies P, Couture J, Pengelly LD, West D, Bromage PR, Milic-Emili J 1971 Partitioning of immediate ventilatory stability to added elastic loads in cats. J Appl Physiol 30:814

21. Mead J, Whittenberger JL 1953 Physical properties of human lungs measured during spontaneous respiration. J Appl Physiol 5:779

22. Mead J, Mcllroy MB, Selverstone NJ, Kriete BC 1955 Measurement of intraesophageal pressure. J Appl Physiol 7:491

23. Milic-Emili J, Grunstein MM 1976 Drive and timing components of ventilation. Chest 70:131 (July suppl)

24. Nystrom B 1968 Fibre diameter increase in nerves to "slow-red" and "fastwhite" cat muscles during postnatal development. Acta Neurol Scand 44:265
25. Nystrom B 1968 Histochemistry of developing cat muscles. Acta Neurol Scand 44:405

26. Olinsky A, Bryan MH, Bryan AC 1974 Influence of lung inflation on respiratory control in neonates. J App. Physiol 36:426

27. Rigatto H, Brady J, Dela Torre Verduzco R 1975 Chemoreceptor reflexes in preterm infants. I. The effect of gestational and postnatal age on the ventilatory response to inhalation of $100 \%$ and $15 \%$ oxygen. Pediatrics 55:604

28. Robertson JD, Reid, DO 1952 Standards for the basal metabolism of norma people in Britain. Lancet 1:940

29. Scopes JW, Ahmed I 1966 Minimal rates of oxygen consumption in sick and premature newborn infants. Arch Dis Child 41:407

30. Stocks J 1977 The functional growth and development of the lung during the first year of life. Early Human Dev 3:285

31. Thach BT, Frantz ID, Adler SM, Taeusch HW 1978 Maturation of reflexes influencing inspiratory duration in human infants. J Appl Physiol 45:203

32. Whitelaw WA, Derenne J-P, Milic-Emili J 1975 Occlusion pressure as a measure of respiratory center output in conscious man. Respir Physiol 23:181

33. Zin WA, Rossi A, Milic-Emili 1983 Model analysis of respiratory responses to inspiratory resistive loads. J Appl Physiol 55:1565

\title{
Comparative Effects of Verapamil, Nifedipine, and Diltiazem on Contractile Function in the Isolated Immature and Adult Rabbit Heart
}

\author{
ROBERT J. BOUCEK, JR., MARC SHELTON, MICHAEL ARTMAN, PHILLIP S. MUSHLIN, \\ VAUGHN A. STARNES, AND RICHARD D. OLSON
}

Departments of Pediatrics, Biochemistry, and Pharmacology, Vanderbilt Universty School of Medicine, Nashville, Tennessee 37232

\section{Summary}

The effects of postnatal development on the systolic and diastolic responses to pharmacologic blockade of the slow inward calcium current were investigated in blood-perfused hearts isolated from immature (14-21-day-old) and adult rabbits. Isovolumic left ventricular developed pressure, resting pressure, and maximal rate of pressure development $(+d P / d t)$ at cumulative doses of either verapamil, nifedipine, or diltiazem were determined by means of an intracavitary balloon. Myocardial contractile function in the immature heart was more sensitive to pharmacologic blockade of the slow inward calcium current than is the adult heart. Doses of verapamil, or nifedipine, that comparably reduced pretreatment developed pressure and $+d P / d t$ were approximately $\mathbf{1 0}$-fold less in immature as compared to the adult heart. The dose of diltiazem which reduced developed pressure and $d P / d t$ by $50 \%$ was 3 -fold less in immature as compared to the adult heart. Verapamil and nifedipine decreased resting pressure in the adult but not in the immature heart. Conversely, diltiazem decreased resting pressure in the immature while not affecting resting pressure in adult hearts. Thus, postnatal cardiac development affects both the systolic and diastolic responses to

Received January 6, 1983; accepted February 8, 1984.

Address reprint requests and correspondence to Robert J. Boucek, Jr. Department of Pediatrics D-2217, Vanderbilt Medical Center, Nashville, TN 37232.

This work was supported in part by a Grant-in-Aid from the American Heart Association-Tennessee Affiliate, Biomedical Research Support Grant RR-5424, and the March of Dimes Birth Defects Foundation. R.D.O. is a Research Investigator of the American Heart Association, Tennessee Affiliate and recipient of National Institutes of Health Grant HL 28711. calcium channel blockade. In addition, diltiazem appears to be qualitatively and quantitatively different from verapamil and nifedipine with respect to the age-related cardiac effects of calcium channel blockade.

\section{Abbreviations}

SR, sarcoplasmic reticulum

SL, sarcolemma

LV, left ventricular

In the mammalian heart, excitation is coupled to contraction by intracellular $\mathrm{Ca}$ cycling mediated by the concerted functions of the SR and SL (5). Several lines of evidence suggest that the relationship between SL and SR in the regulation of excitationcontraction coupling may undergo significant changes during postnatal development.

Ultrastructural evidence suggests significant postnatal development of the SR and T-tubule network (13, 16, 24, 25). Ca"triggered" Ca release by SR can first be demonstrated in skinned cardiac fibers $48 \mathrm{~h}$ after birth $(3,4)$. There is also suggestive evidence that the $\mathrm{Ca}$ reuptake properties of SR, important in relaxation, also develops after birth $(16,22,28)$. Postnatal differences in cardiac contractile responses to extracellular $\mathrm{Ca}(23,26)$, lanthanum (7), manganese (7), and caffeine (13), tension development under voltage-clamp conditions (16) suggest that: (a) a new source of "activator" Ca develops with the postnatal development of the SR and T-tubule system; and (b) trans-sarcolem- 
mal $\mathrm{Ca}$ influx may be the primary source of $\mathrm{Ca}$ for activation of the contractile elements prior to develoment of the SR and Ttubule network.

To determine if Ca delivery to the contractile elements in the immature heart is more dependent on the trans-sarcolemmal influx of $\mathrm{Ca}$ via the $\mathrm{Ca}$ channel than in the adult heart, we investigated the dose-response relationship of three blockers of the slow inward Ca current, verapamil, nifedipine, and diltiazem, on contractile force development by isolated immature and adult rabbit hearts. All three agents reduce contractile force and the slow inward Ca current in the adult heart $(1,12,19)$. If contraction in the immature heart is more dependent on trans-sarcolemmal $\mathrm{Ca}$ influx than in the adult heart, myocardial contractile force in the immature heart should be more sensitive than the adult heart to the negative ionotropic effects of these agents.

\section{MATERIALS AND METHODS}

Experimental model. Rabbit hearts were isolated and perfused in this study using methods similar to that described by Henry et al. (11) modified to permit recirculating perfusion with blood. Hearts were removed from either adult (2-3 kg) or 13-26-dayold (200-400 g) New Zealand White rabbits after administration of intravenous heparin (200 units $/ \mathrm{kg}$ ) and sodium pentobarbital (approximately $30 \mathrm{mg} / \mathrm{kg}$ ). Each heart was suspended by a cannula and continuously perfused with whole heparinized blood $\left(31^{\circ} \mathrm{C}\right)$ obtained from a donor adult rabbit. Blood was recirculated, bubble-oxygenated with $97 \% \mathrm{O}_{2} / 3 \% \mathrm{CO}_{2}\left(\mathrm{PO}_{2}>120 \mathrm{~mm}\right.$ $\mathrm{Hg}$ ), and filtered (Pall Ultipor; $45 \mu$ ). Each heart was electrically stimulated (Grass Model 588 stimulator) at a rate $10 \%$ faster than the spontaneous rate by means of wires attached to the epicardial surface of the left atrium. In preliminary experiments, coronary perfusion flow rates that sustained maximal LV-developed pressures routinely resulted in coronary perfusion pressures which approximated the mean aortic pressure in vivo. Therefore, mean coronary flow was adjusted upward in each experiment to optimize LV-developed pressure without exceeding coronary perfusion pressures of $75 \mathrm{~mm} \mathrm{Hg}$ in the immature and $100 \mathrm{~mm}$ $\mathrm{Hg}$ in the adult heart. This perfusion flow rate was then maintained constant for the duration of each experiment.

A compliant fluid-filled latex balloon affixed to a catheter was inserted through the left atrial appendage into the left ventricular cavity. The proximal end of the catheter was connected to a Statham pressure transducer. The balloon volume was slowly increased by saline infusion to a resting pressure that optimized developed pressure, approximately $10 \mathrm{~mm} \mathrm{Hg}$. Developed and resting pressures $(\mathrm{mm} \mathrm{Hg})$, electrically differentiated maximal rate of pressure development $(+d P / d t ; \mathrm{mm} \mathrm{Hg} / \mathrm{sec})$, and perfusion pressures $(\mathrm{mm} \mathrm{Hg}$ ) were continuously monitored. Resting pressure at end-diastole was corrected for balloon compliance by subtracting the balloon pressure, or the measured pressure obtained when the balloon is inflated outside of the heart with a measured volume of saline equal to the volume of saline previously used to inflate the balloon positioned in the left ventricular cavity.

All dose-response experiments were performed with hearts isovolumically contracting at constant rate with constant coronary flow, and resting end-diastolic volume. Hearts were perfused at constant flow during the dose-response experiments, rather than constant pressure, to ensure that the recognized coronary vasodilator effects of the calcium channel blockers would not alter coronary flow and thereby alter contractile function or resting pressure. The $\mathrm{pH}, \mathrm{PCO}_{2}$, and $\mathrm{PO}_{2}$ of the perfusate were monitored throughout the experimental period with a Corning Model 165 blood gas analyzer.

Experimental protocols. Aqueous verapamil and diltiazem stock solutions were prepared and shielded from light. The nifedipine stock solution was prepared in $15 \%(\mathrm{v} / \mathrm{v})$ ethanol and shielded from light. Because of the negative inotropic effects of ethanol vehicle alone (data not shown), the maximum concentration of nifedipine was limited to $0.2 \mu \mathrm{M}$.
Calcium channel blocker dose-response. After a stabilization period of approximately $30 \mathrm{~min}$, adult or neonatal hearts received cumulative doses of the calcium channel blockers $( \pm)$ verapamil (Knoll), nifedipine (Bayer), or diltiazem (Marion). The developed pressure, $+d P / d t$, and perfusion pressure were recorded after stabilization at each dose of the calcium channel blocker, usually within $10 \mathrm{~min}$ after addition, and expressed as the percentage of the pretreatment "control" values. The cumulative dose-response curve was completed in less than $3 \mathrm{~h}$. Suitable control experiments have not shown significant changes in the contractility indices or coronary resistance during the 3 -h experimental period.

Statistical analyses. The cumulative doses of calcium channel blocker which reduced baseline (control) developed pressure or $+d P / d t$ by 20 and $50 \%$ were defined as the $\mathrm{ID}_{20}$ and $\mathrm{ID}_{50}$, respectively. The $\mathrm{ID}_{20}$ and $\mathrm{ID}_{50}$ were determined for each individual heart and the mean \pm SE was calculated for each treatment and age group. All comparisons between the immature and adult groups were made by unpaired $t$ test using two-tailed Student's $t$ distribution. Comparisons of baseline developed and resting pressures and $d P / d t$ of those hearts treated with verapamil, nifedipine, or diltiazem within an age group were made by oneway analysis of variance using Duncan's procedure for equal sample size. Differences between groups were considered statistically significant if the $p$ value was less than 0.01 .

\section{RESULTS}

Control values. The baseline control values for left ventricular developed pressure and $+d P / d t$ in the immature groups of immature hearts receiving either verapamil, nifedipine, or diltiazem were not significantly different. Similarly, the mean control values for developed pressure and $+d P / d t$ in the groups of adult hearts receiving either verapamil, nifedipine, or diltiazem were

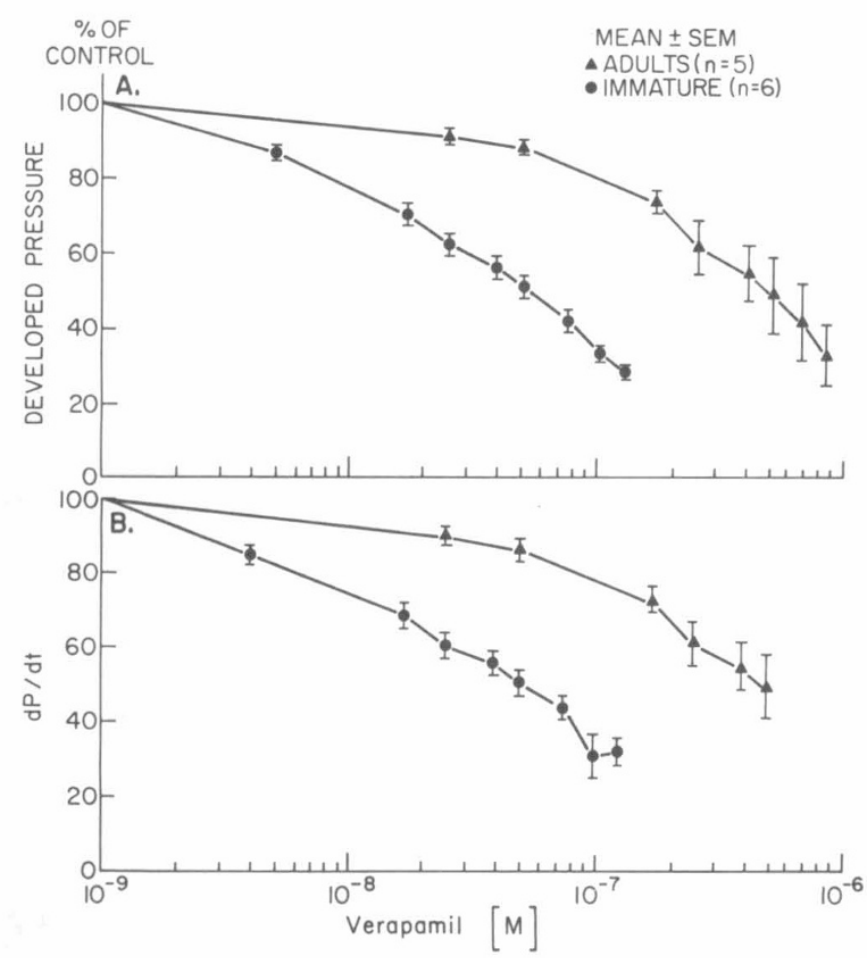

Fig. 1. The effect of verapamil on isovolumic LV-developed pressure and $+d P / d t$ in isolated perfused adult $(\boldsymbol{\Delta})$ and immature $(\bullet)$ rabbit heart. Developed pressures (upper panel) and $+d P / d t$ (lower panel), expressed as percentage of the pretreatment control value, are shown as a function of the molar concentration of verapamil, plotted on a logarithmic scale. The mean $\pm \mathrm{SE}$ control developed pressure and $+d P / d t$ were: immature $=67 \pm 9 \mathrm{~mm} \mathrm{Hg}$ and $979 \pm 150 \mathrm{~mm} \mathrm{Hg} / \mathrm{sec}$; adult $=99 \pm 9 \mathrm{~mm} \mathrm{Hg}$ and $1150 \pm 121 \mathrm{~mm} \mathrm{Hg} / \mathrm{sec}$. 
not different. Stimulation rates were not significantly different between immature and adult hearts in either the verapamil (176 \pm 9 versus $\left.148 \pm 11 \mathrm{~min}^{-1}\right)$ or the diltiazem $(137 \pm 9$ versus 139 $\left.\pm 8 \mathrm{~min}^{-1}\right)$ treatment groups. The mean stimulation rate of the immature group treated with nifedipine was higher than that in the adult group treated with nifedipine $(167 \pm 10$ versus $120 \pm$ $\left.9 \min ^{-1} ; p<0.05\right)$.

Verapamil, nifedipine, and diltiazem dose-response. Both developed pressure and $+d P / d t$ were significantly reduced in the immature rabbit hearts by cumulative doses of verapamil (Fig. 1) and nifedipine (Fig. 2) which did not affect developed pressure and $+d P / d t$ in the adult hearts. The mean concentrations required to reduced control developed pressure and $+d P / d t$ by 20 and $50 \%$ for verapamil and $20 \%$ for nifedipine were significantly

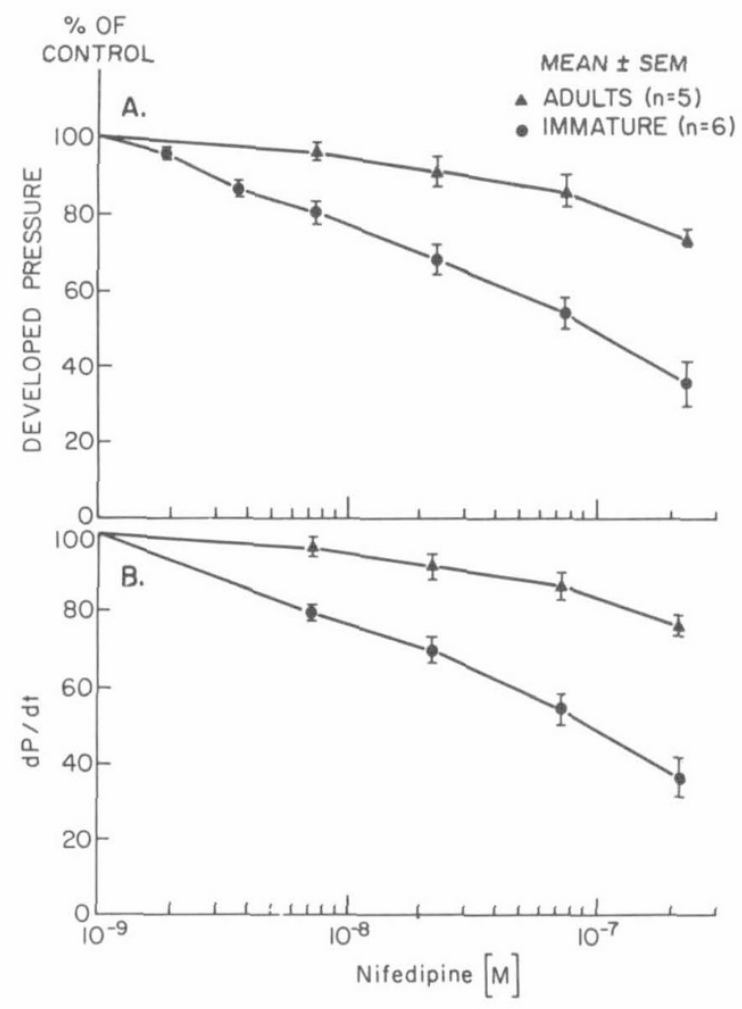

Fig. 2. The effect of nifedipine on isovolumic LV-developed pressure and $+d P / d t$ in adult $(\mathbf{\Lambda})$ and immature $(\bullet)$ rabbit heart. Developed pressures (upper panel) and $+d P / d t$ (lower panel), expressed as percentage of the pretreatment control value, are shown as a function of the molar concentration of nifedipine, plotted on a logarithmic scale. The mean $\pm \mathrm{SE}$ control developed pressure and $+d P / d t$ were: immature $=$ $87 \pm 6 \mathrm{~mm} \mathrm{Hg}$ and $1055 \pm 130 \mathrm{~mm} \mathrm{Hg} / \mathrm{sec}$; adult $=111 \pm 7 \mathrm{~mm} \mathrm{Hg}$ and $1336 \pm 125 \mathrm{~mm} \mathrm{Hg} / \mathrm{sec}$. different between the immature and adult hearts $(p<0.005$; Table 1).

In contrast to the age-related difference in contractile response to all doses of verapamil and nifedipine, the diltiazem concentration required to produce a similar reduction in developed pressures was 1-4-fold less for immature hearts than adult hearts (Fig. 3). There were no statistically significant differences in the concentration required to reduce control developed pressure from 5 to $25 \%$ for the immature compared to the adult hearts (Fig. 3; Table 1). However, the mean concentration of diltiazem which reduced control developed pressure in the immature hearts by $50 \%$ was significantly less $(p<0.005)$ than the mean concentration which reduced developed pressure by $50 \%$ in the adult hearts (Table 1).

Bioassay of perfusate concentration of verapamil. Verapamil

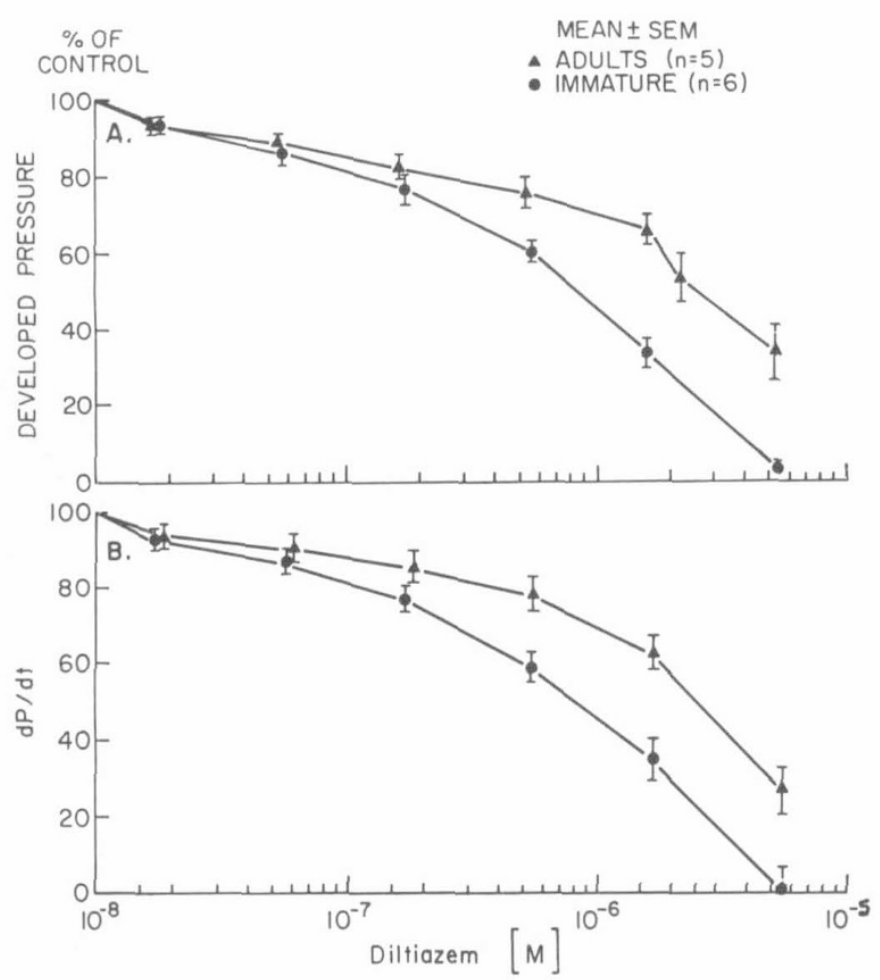

Fig. 3. The effect of diltiazem and isovolumic developed pressure (upper panel) and $+d P / d t$ in adult $(\mathbf{\Lambda})$ and immature $(\mathbf{)})$ rabbit heart. Developed pressure (upper panel) and $+d P / d t$ (lower panel), expressed as percentage of the pretreatment control value are shown as a function of the molar concentration of diltiazem, plotted on a logarithmic scale. The mean control developed pressure and $+d P / d t$ were: immature $=81$ $\pm 7 \mathrm{~mm} \mathrm{Hg}$ and $1024 \pm 97 \mathrm{~mm} \mathrm{Hg} / \mathrm{sec}$; adult $=95 \pm 1 \mathrm{~mm} \mathrm{Hg}$ and $1074 \pm 94 \mathrm{~mm} \mathrm{Hg} / \mathrm{sec}$.

Table 1. Inhibitory doses for Ca channel-blocking drugs in immature and adult rabbit heart*

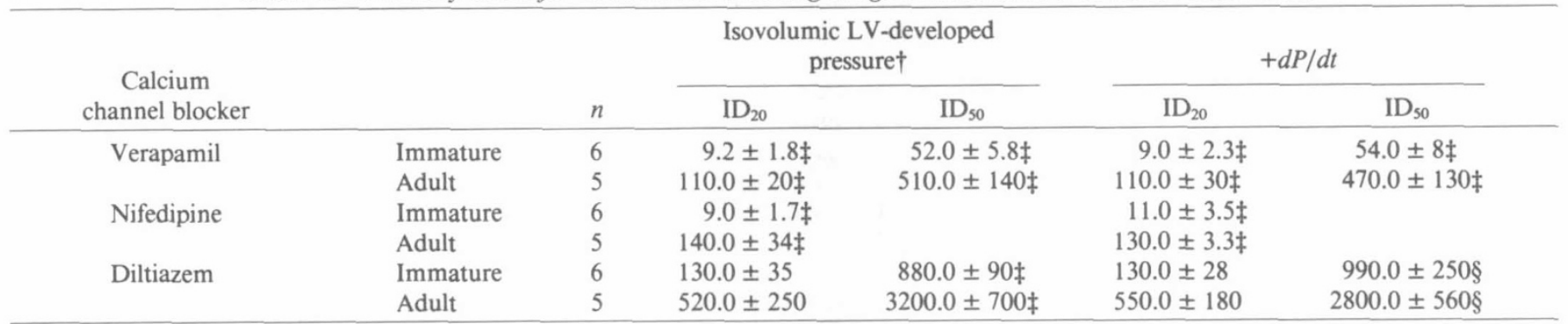

* All inhibitory doses are mean ( \pm SE) $10^{-9} \mathrm{M}$ concentrations.

$+\mathrm{ID}_{20}$ and $\mathrm{ID}_{50}$ are the cumulative inhibitory doses of calcium channel blocker which reduced the contractile response by 20 or $50 \%$, respectively. $\ddagger p<0.005$ immature versus adult.

$\S p<0.01$ immature versus adult. 


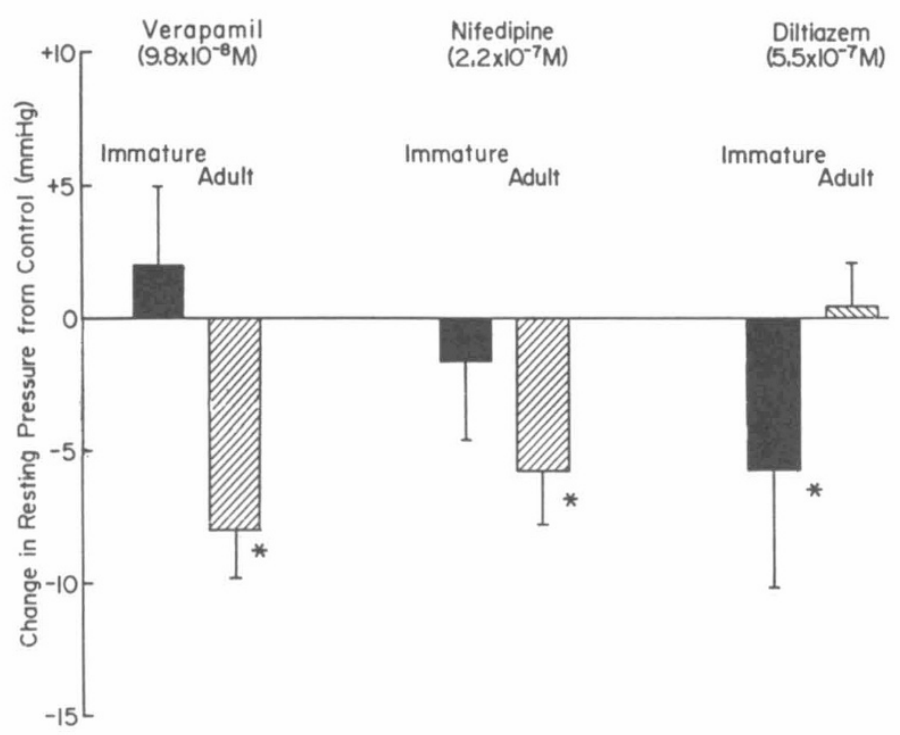

Fig. 4. The effect of selected concentrations of verapamil (98 nM), nifedipine $(220 \mathrm{nM})$, and diltiazem $(550 \mathrm{nM})$ on the resting pressure of

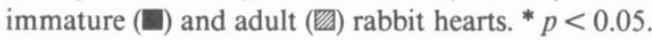

$\left(6.4 \times 10^{-8} \mathrm{M}\right)$ when added to the perfusate of the adult heart reduced developed pressure $\leq 25 \%$ of the control developed pressure at equilibrium. When this perfusate containing verapamil was switched to perfuse the immature heart previously stabilized with verapamil-free perfusate, control developed pressure was reduced $\leq 90 \%$ in the immature hearts. This concentration of verapamil would have been predicted to reduce developed pressure in the immature heart by greater than $50 \%$ (Fig. 1). Thus, the greater tissue mass of the adult heart did not significantly reduce the verapamil concentration in the perfusate as evidenced by the appropriate depression in developed pressure exhibited in the cross-perfused immature heart.

Resting pressure. Verapamil and nifedipine, but not diltiazem, resulted in a dose-dependent reduction in resting pressures at end-diastole in adult hearts. Verapamil and nifedipine did not affect resting pressures at any dose in immature hearts. The effect of selected concentrations of verapamil ( $98 \mathrm{nM})$, nifedipine (220 $\mathrm{nM})$, and diltiazem (550 $\mathrm{nM})$ which resulted in a greater than $20 \%$ decrease in developed pressure in immature and adult hearts on resting pressure is illustrated in Figure 4. Resting pressure in adult hearts was significantly reduced by both verapamil and nifedipine (Fig. 4). Resting pressure in immature hearts was not significantly affected by either verapamil or nifedipine (Fig. 4). In contrast, resting pressure was significantly reduced by diltiazem in the immature heart whereas resting pressure was unchanged by diltiazem in the adult heart (Fig. 4).

\section{DISCUSSION}

In this study, we have demonstrated that verapamil, nifedipine, and diltiazem reduced developed pressure and $+d P / d t$ of the isolated immature rabbit heart at significantly lower concentrations than required to comparably reduce developed pressure and $+d P / d t$ in the adult. This is the first report of the effect of postnatal development on the inotropic response to three commonly used $\mathrm{Ca}$ channel blockers. Recent reports support our findings of significant age-related differences in the inotropic response to verapamil but differ with regard to whether the inotropic response of the adult or the newborn heart is more sensitive to the calcium channel-blocking agents. Gibson et al. (9) reported that cardiac output in the immature dog (ages 2-12 days) was more depressed by verapamil as compared with the adult dog. In contrast, George et al. (8) preliminarily reported that verapamil $\left(10^{-7} \mathrm{M}\right)$ reduced developed tension less in the perfused septal preparation from the newborn rabbit heart as compared to the adult. The reason for this apparent discrepancy is unclear, though it is possible that the slower stimulation frequency $(36 / \mathrm{min})$ used in the study of George et al. (8) may have affected the sensitivity to verapamil since inhibition of slow channel-mediated $\mathrm{Ca}$ influx by verapamil is frequency dependent at rates less than $100 \mathrm{~min}^{-1}(10,17)$. The stimulation frequencies used in this study were: (a) not different between age groups treated with either verapamil or diltiazem; (b) in a more physiologic range than used in the study of George et al. (8); and (c) in a range that has little effect on the inotropic sensitivity to verapamil $(10,17)$.

The greater inotropic sensitivity in immature rabbit hearts to the $\mathrm{Ca}$ channel blockers suggest a greater dependency of contraction in the immature heart on Ca channel-mediated trans-sarcolemmal $\mathrm{Ca}$ influx. This greater dependency of the immature heart may reflect the greater external cell surface area of the immature myocardial cells (13), developmental differences in sarcolemmal $\mathrm{Ca}$ regulation $(2,6,14,15)$, and/or the relative immaturity of the SR in the developing heart $(4,13,16,22,25)$. This hypothesis is entirely consistent with the age-related difference in the contractile response to the inorganic calcium channel blocker manganese (7) and further supported by the rightward shift of the contractile response versus extracellular [Ca] relationship in newborn compared with adult hearts $(23,26)$.

The subcellular mechanism whereby dependency of contractile force on $\mathrm{Ca}$ channel-mediated $\mathrm{Ca}$ influx changes during postnatal development is still speculative. Ca channel-mediated $\mathrm{Ca}$ influx may: (a) directly initiate mechanical contraction; (b) replenish the intracellular stores of releasable $\mathrm{Ca}$ in the SR; and/or (c) trigger the release of $\mathrm{Ca}$ from SR stores for the contractile event (18). Thus, there may be age-related differences either in the relative contributions of SL and SR Ca delivered to the contractile elements and/or in the loading and release of SR Ca.

Indirect evidence, based on measurement of action potentials in neonatal and adult canine Purkinje fibers, indicates a greater inward Ca current during early postnatal development as compared to that in the adult (27). In addition, the amplitude of the slow response (Ca-dependent) action potential became progressively more sensitive to inhibition by verapamil with increasing age (27). In voltage-clamped feline papillary muscles, contractility of the neonatal papillary muscle was "more directly controlled by membrane potential" as compared to the adult (16). These observations suggest a decrease in $\mathrm{Ca}$ channel-mediated $\mathrm{Ca}$ influx with postnatal cardiac development but this conclusion must await confirmation using cellular voltage-clamp technques. It should be ponted out, however, that if the rightward shift in the contractility versus $\mathrm{Ca}$ channel blocker dose-response relationship (Figs. 1-3) associated with postnatal development was due solely to age-related differences in $\mathrm{Ca}$ current, then a smaller (not larger) $\mathrm{Ca}$ current would be predicted in the immature as compared to the adult.

Perinatal development of the SR is suggested by morphologic and functional evidence $(13,16,20,22,24,25,27,28)$. If developmental differences in SR Ca release are invoked to account for the rightward shift of the $\mathrm{Ca}$ channel blocker doseresponse relationship (Figs. 1-3) during postnatal development, then $\mathrm{Ca}$ release from immature SR would be predicted to be more depressed by equivalent pharmacologic blockade of the $\mathrm{Ca}$ "trigger" as compared with the adult SR (29). In skinned rat heart fibers, the maximum myoplasmic [free $\mathrm{Ca}$ ] and the [Ca] for "optimum" triggering of Ca release reached adult values between 2 and 10 days after birth (4). Although SR Ca release has not been evaluated in the rabbit heart, SR Ca release in the 14-21-day-old rabbit heart may not be fully developed. Further studies will be required to elucidate the role of the SR and Ttubule development on excitation-contraction coupling in the developing heart.

Alternative mechanistic explanations for the greater inotropic sensitivity to the calcium channel blockers in the immature heart (Table 1) include: (a) a different Ca sensitivity of the contractile elements $(3,4)$; and (b) a greater drug-"receptor" interaction or 
affinity constant or a smaller number of receptors resulting in a greater reduction in the $\mathrm{Ca}$ current at any given drug dose.

A greater $\mathrm{Ca}$ sensitivity of the contractile proteins has been reported for skinned fetal and adult rat heart fibers $(3,4)$. Comparable studies have not been carried out during postnatal development. The $\mathrm{Ca}$ sensitivities of the myofibrillar ATPase from immature and adult rabbit heart, however, have been found to be equivalent (21). Thus, the observed age-related differences in the inotropic sensitivity to the calcium channel blockers may be due to differences in the relationship between contractile force and the calcium concentration of the contractile elements but experimental evidence for this postulate is still conflicting and incomplete.

Another possible mechanism of these age-related differences in inotropic sensitivity to the calcium channel blockers is related to myocardial binding affinity of these compounds with resultant differences in drug-receptor interaction. Because of the structural dissimilarities among the three blockers (1) as well as the suggested differences in site(s) of action $(12,19)$, this mechanism seems unlikely. Furthermore, preliminary results suggest comparable high affinity binding constants for $\left[{ }^{3} \mathrm{H}\right]$ nitrendipine in membrane vesicles from the immature and adult rabbit heart (2).

\section{REFERENCES}

1. Antman EM, Stone PH, Muller JE, Braunwald E 1980 Calcium channel blocking agents in the treatment of cardiovascular disorders. 1. Basic and clinical electrophysiologic effects. Ann Intern Med 93:875

2. Boucek RJ, Shelton M, Landon E, Artman M, Graham TP 1983 Sarcolemmal membrane characteristics during post-natal development. Circulation 68:111

3. Fabiato A, Fabiato F 1978 Calcium-induced release of calcium from the sarcoplasmic reticulum of skinned cells from adult human, dog, cat, rabbit, rat and frog hearts and from fetal and newborn rat ventricles. Ann Acad Sci $307: 491$

4. Fabiato A 1982 Calcium release in skinned cardiac cells. Variations with species, tissues, and development. Fed Proc 41:2238

5. Fozzard HA 1977 Heart: excitation-contraction coupling. Annu Rev Physiol 39:201

6. Galper JB, Catterall WA 1978 Developmental changes in the sensitivity of embryonic heart cells to tetrodotoxin and D600. Dev Biol 65:216

7. George BL, Jarmakani JM 1983 The effects of lanthanum and manganese on excitation-contraction coupling in the newborn rabbit heart. Dev Pharmacol Ther 6:33

8. George BL, Nakanishi T, Shimizu T, Nishioka K, Jarmakani JM 1981 Effect of verapamil on mechanical function of the neonatal rabbit heart. Pediatr Res 15:463

9. Gibson R, Driscoll D, Gillette P, Hartley C, Entman ML 1981 The comparative electrophysiologic and hemodynamic effects of verapamil in puppies and adult dogs. Dev Pharmacol Ther 2:104

10. Harada S, Sada H, Kojima M, Ban T 1982 Negative inotropic effects of tiapamil (Roll-1781) and verapamil in rabbit myocardium. Eur J Pharmacol 78:7

11. Henry PD, Shuchleib R, Davis J, Weiss ES, Sobel BE 1977 Myocardial contracture and accumulation of mitochondrial calcium in ischemic rabbit heart. Am J Physiol 233:H677

12. Henry PD 1980 Comparative pharmacology of calcium antagonists: nifedipine, verapamil, and diltiazem. Am J Cardiol 46:1047

13. Hoerter J, Mazet F, Vassort G 1982 Perinatal growth of the rabbit cardiac cell: possible implications for the mechanism of relaxation. J Mol Cell Cardiol $13: 725$

14. Jarmakani JM, Nagatomo T, Langer GA 1978 The effect of calcium and highenergy phosphate compounds on myocardial contracture in the newborn and adult rabbit. J Mol Cell Cardiol 10:1017

15. Marsh AW, Lloyd BL, Taylor RR 1981 Age dependence of myocardial $\mathrm{Na}^{+}$$\mathrm{K}^{+}$-ATPase activity and digitalis intoxication in the dog and guinea pig. Circ Res 48:329

16. Maylie JG 1982 Excitation-contraction coupling in neonatal and adult myocardium of cat. Am J Physiol 242:H834

17. McCans JL, Lindenmayer GE, Munson RG, Evans RW, Schwartz A 1974 A dissociation of positive staircase (Bowditch) from ouabain-induced positive inotropism. Circ Res 35:439

18. McDonald TF, Pelzer D, Trautwein W 1981 Does the calcium current modulate the contraction of the accompanying beat? Circ Res 49:576

19. Millard RW, Lathrop DA, Grupp G, Ashraf M, Grupp IL, Schwartz A 1982 Differential cardiovascular effects of calcium channel blocking agents: potential mechanisms. Am J Cardiol 49:499

20. Nagatomo T, Hattori K, Ikeda M, Shimada K 1980 Lipid composition of sarcolemma, mitochondria and sarcoplasmic reticulum from newborn, and adult rabbit cardiac muscle. Biochem Med 23:108

21. Nakanishi T, Jarmakani J 1982 Myofibrillar content and sensitivity to calcium in the developing heart. Circulation 66:112

22. Nayler WG, Fassold E 1977 Calcium accumulating and ATPase activity of cardiac sarcoplasmic reticulum before and after birth. Cardiovasc Res 11:213

23. Nishioka K, Nakanishi T, George BL, Jarmakani JM 1981 The effect of calcium on the inotrophy of catecholamine and paired electrical stimulation in the newborn and adult myocardium. J Mol Cell Cardiol 13:411

24. Olivetti G, Anversa P, Loud AV 1980 Morphometric study of early postnatal development in the left and right ventricular myocardium of the rat. II. Tissue composition, capillary growth, and sarcoplasmic alterations. Circ Res 46:503

25. Page E, Buecker JL 1981 Development of dyadic junctional complexes between sarcoplasmic reticulum and plasmalemma in rabbit left ventricular myocardial cells: morphometric analysis. Circ Res 48:519

26. Park MK, Sheridan PH, Morgan WW, Beck N 1980 Comparative inotropic response of newborn and adult rabbit papillary muscle to isoproterenol and calcium. Dev Pharmacol Ther 1:70

27. Reder RF, Miura DS, Danilo P Jr, Rosen MR 1981 The electrophysiological properties of normal neonatal and adult canine cardiac Purkinje fibers. Circ Res 5:658

28. Will H, Kuttner I, Vetter R, Will-Shahab L, Kemsies C 1983 Early presence of phospholamban in developing chick heart. FEBS Lett 155:326

29. Winegard S 1982 Calcium release from cardiac sarcoplasmic reticulum. Annu Rev Physiol 44:451 